\title{
Experimental and Numerical Method for the Analysis of Warm Titanium Sheet Stamping of an Automotive Component
}

\author{
Antonio Fiorentino, ${ }^{1}$ Elisabetta Ceretti, ${ }^{1}$ and Claudio Giardini ${ }^{2}$ \\ ${ }^{1}$ Department of Mechanical and Industrial Engineering, University of Brescia, Via Branze 38, 25123 Brescia, Italy \\ ${ }^{2}$ Department of Engineering, University of Bergamo, Via Pasubio 7b, 24044 Dalmine, Italy \\ Correspondence should be addressed to Claudio Giardini; claudio.giardini@unibg.it
}

Received 5 January 2015; Revised 23 March 2015; Accepted 6 April 2015

Academic Editor: José L. Ocaña

Copyright (C) 2015 Antonio Fiorentino et al. This is an open access article distributed under the Creative Commons Attribution License, which permits unrestricted use, distribution, and reproduction in any medium, provided the original work is properly cited.

\begin{abstract}
Product design involves many aspects as geometry and material or mechanical requirements that have to be chosen on the base of the part requirements. Manufacturing process is the link between them representing a fundamental aspect of the product design process. Designers and technicians have a consolidated set of tools and knowledge based on long time experience, but the request of more new performing products characterized by more complex geometries or harder to form materials as Titanium alloys stimulated the use of numerical models. They allow us to study the product feasibility but they require reliable inputs for their development and validation. The present research focuses on sheet stamping processes and proposes a methodology that uses the Nakazima test to characterize the formability of the material and to develop and validate the model. In particular, the method is applied to cold $\left(20^{\circ} \mathrm{C}\right)$ and warm $\left(300^{\circ} \mathrm{C}\right)$ stamping of a complex automotive component made of CP Titanium. After characterizing the material and validating the model at the different temperatures, the stamping process is studied and results are compared. In particular, this approach allowed joining the experimental tests required to develop and validate the model, therefore reducing the resources required for the product design.
\end{abstract}

\section{Introduction}

The need of reducing the impact on the environment in terms of pollution and energy consumption is one of the most important requests to be accomplished in these last years for both the parts production and use. For this reason automotive industry requests are focused on the use of both innovative material able to reduce the vehicle mass and innovative process solutions able to reduce the energy needed to work the parts and to work the innovative materials. In fact, the mass of automotive components can be reduced not only using material with low values of the mass density (e.g., aluminium alloys as discussed in [1]), but also using more resistant materials (e.g., high strength steel). The use of Titanium is a good compromise between these two targets [2]. In fact, Titanium is nowadays one of the most attractive materials also for high tech products thanks to its high mechanical properties, low weight to strength ratio, high corrosion resistance, and high biocompatibility [3].
In particular, Commercially Pure Titanium (Ti CP) sheets and its alloys are used for the production of tubes, heating systems, valves, and devices working in highly aggressive environments. As nickel alloys, Ti resists at high temperature, but its lower density make it more suitable for aerospace engine components as plugs and nozzles where temperature can reach $600^{\circ} \mathrm{C}$ [4]. Other applications of $\mathrm{Ti}$ alloys are found in the fields of automotive, aesthetical components for computers, telephones, or house goods or biomedical prosthesis as discussed in [5].

Besides these advantages, Ti sheets are characterised at room temperature by low formability and ductility and high springback (the Young modulus is half of the steel one). Therefore, Ti sheet applications can be limited especially when high deformations or complex parts are considered [6]. In order to overcome these limitations, [7] proposed a multistage forming process while [8] studied the effect of temperature in reducing the tensile/yield strengths ratio of the material so to reduce the elastic recovery of the part. 
Ti can be formed at higher temperature (close or above to $\alpha$ - $\beta$ transition zone) but an excessive oxygen absorption can occur and form a fragile layer. Moreover, above $650^{\circ} \mathrm{C}$ and at low deformation rates the material recrystallizes and its hardness decreases, while over $450^{\circ} \mathrm{C} \mathrm{Ti}$ reacts with atmosphere, oxidising and modifying its esthetical aspects [9].

The working range between $200^{\circ} \mathrm{C}$ and $450^{\circ} \mathrm{C}$ allows reducing the risk of the previously described phenomena while increasing Ti formability [10] and, as a consequence, complex part geometries can be manufactured. In this range, membrane deformations [11] and local instability must be carefully studied to predict material fracture [12] and the knowledge of the mechanical properties and the formability of the material is fundamental in order to model Titanium formability in sheet forming. In fact, [13] showed that the prediction of wrinkle formation and the identification of tearing limit conditions are some of the main problems in the simulation industry. Moreover, [14] proposed an inverse approach that simplifies the manufacturing design process focusing on the formability and quality of the product without defining the initial blank and the geometry of tools. For these reasons, Ti material has been intensively studied during the years to determine its mechanical properties [15] and to analyze the deformation mechanism [16]. Other studies aimed at the improvement of its formability by loading the material near to pure shear [17] or using dynamic aging both at cold [18] and warm temperatures [19]. Moreover, hot forming of $\mathrm{Ti}$ alloys involves problems related to the material microstructural evolution [20] or to other aspects of the forming process as tool material, blank holding, heating, and regulation, insulation as discussed in [21].

Despite of the relatively high number of papers on the subject, the actual industrial practice in designing plastic deformation processes of Titanium sheet parts is based on empirical approaches, and several trials are needed to solve the production errors and to identify the best part geometry and process parameters.

To overcome these problems and to reduce the industrialization time and costs of complex parts, modelling becomes a key factor. In fact, the use of Finite Elements Method (FEM) programs allows us to analyse, in a virtual environment, the feasibility of complex parts and to identify the effects of the component geometry, of the sheet material and of the process parameters on the component soundness. The modelling process can be very fast (few simulation days) if the part geometries, the production machines, the sheet material behaviour, and the process parameters to test are known. In particular, the correct identification of the limits for material formability is fundamental for evaluating part feasibility using simulation models especially when innovative and difficult to work materials are under study [22]. In fact, a good material characterization for stamping process modelling can start from the tensile test, but it must go further by considering a biaxial state of stress and strain. In particular, the Nakazima test [23] can analyse different deformation conditions and define the Forming Limit Curve (FLC) of the material which can represent a reliable criterion for metal sheet formability to be used in FEM models. Moreover, the material formability is influenced by the forming temperature; therefore, the FLCs have to be identified according to the temperature that is considered for the stamping process.

According to this vision, the present paper presents the study of a complex automotive part to be produced in Titanium instead of the typically used deep-drawing steel. In particular, it describes a working approach based on experiments and FE simulations and able to furnish to technicians and designers a valid tool for studying the feasibility of complex parts in cold and warm stamping. The approach is based on Nakazima test both to estimate the FLCs of the material and to validate the FEM model at the considered temperature. Then, model and FLCs are used together to study the stamping process of the automotive part, to identify the proper process conditions, and to study the part feasibility.

\section{Material Formability Characterization}

2.1. Experimental FLC of Ti CP Gr.2 Sheet. The tests were carried out by means of an experimental equipment designed and realised for this purpose (Figure 1) according to [23]. It is composed of a die and a moving punch fixed to the press frame to the press piston (maximum force equal to $1500 \mathrm{kN}$ ), respectively. A blank-holder with a drawbead guarantees that the sheet cannot move during the test. The test device is equipped with a heating system so to conduct tests at warm or hot temperatures. In particular, the samples are placed directly on the dies using an insulated holding frame, and then they are heated using an electrical current generator connected to the sheet edges so to guarantee a uniform temperature distribution in the sheet. Preliminary tests were carried out with thermocouples placed on the sheet surface showing a limited spatial temperature gradients in the deformation area. The working temperature during the test execution is controlled by means of a thermocouple placed on the sheet surface and when the desired temperature is achieved, the warming system is immediately switched off and the punch starts to move (test beginning) to avoid short circuit between the testing equipment and the press. The punch was preheated and positioned at $2 \mathrm{~mm}$ from the sheet so guaranteeing the most uniform and constant temperature during the punch movement so performing an isothermal test. This solution was chosen since it allows a rapid and uniform sheet heating, and it does not need cooling device and allows the continuous monitoring of the deformation process. Moreover, the heating system is integrated with the machine and, therefore, no sheet movement and its subsequent cooling occur.

The tests were executed on Ti CP GR. 2 sheets in annealed state, with a thickness of $1 \mathrm{~mm}$ and at temperatures of 20 and $300^{\circ} \mathrm{C}$. A total of 24 tests were carried out on sheets having a width of $12,36,84,100,132$, and $150 \mathrm{~mm}$ [23], cut along $0^{\circ}$ and $90^{\circ}$ with respect to the rolling direction.

After the tests, the grid on the samples was measured (accuracy $0.02 \mathrm{~mm}$ ) considering the areas close to the sheet rupture. Actually, this measuring method estimates the deformations of the sheet in the safe zones that are close to failure 


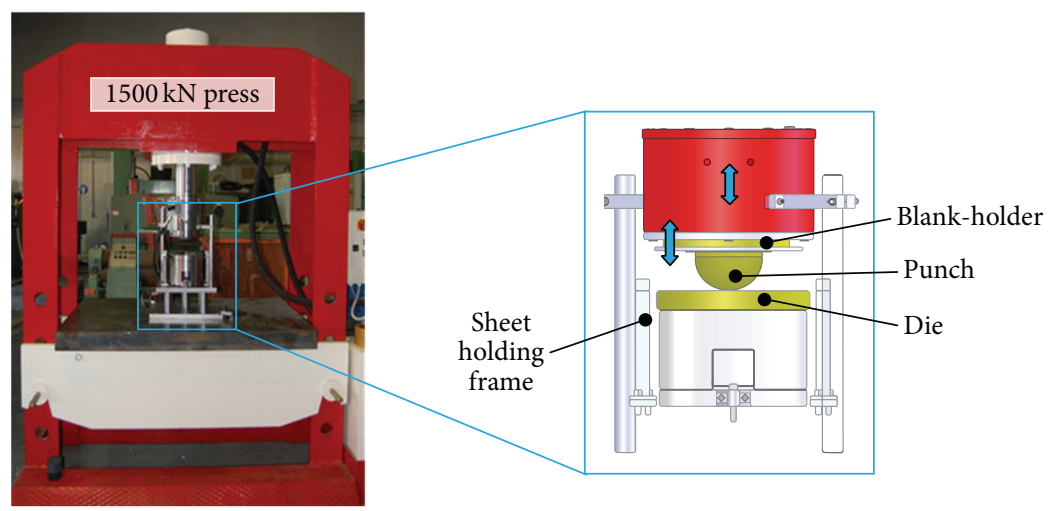

FIGURE 1: Equipment used for the Nakazima test.
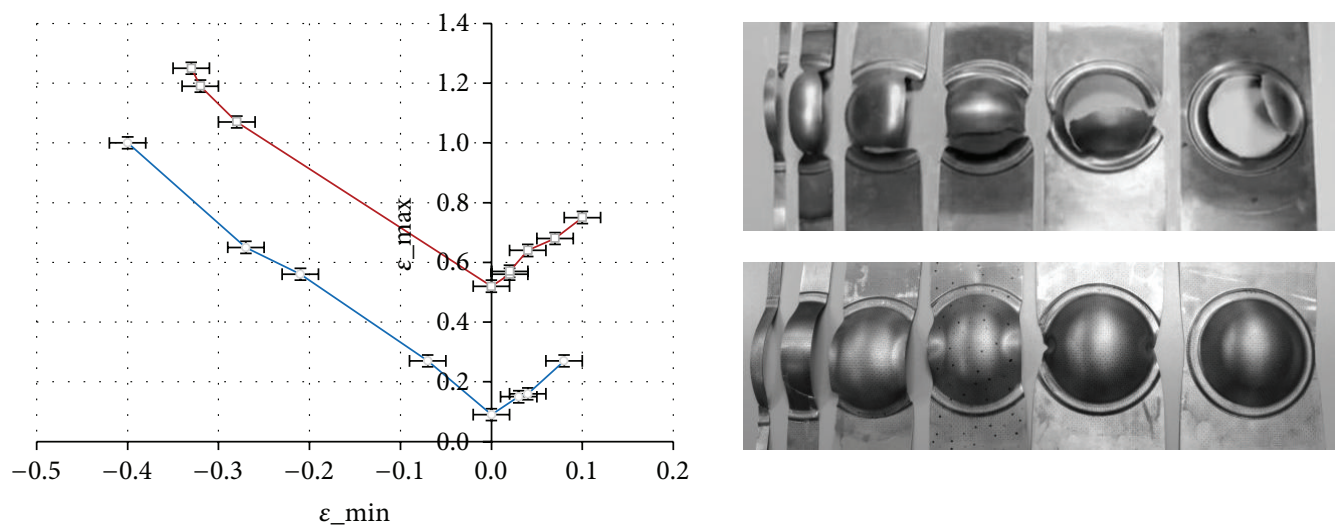

-- Ti CP Gr.2-1.0 mm- $T=20^{\circ} \mathrm{C}$

$-\square$ Ti CP Gr.2-1.0 mm- $T=300^{\circ} \mathrm{C}$

FIgURE 2: Experimental FLC curves for annealed Ti CP GR.2 $1 \mathrm{~mm}$ thick.

and it allows us to overcome the limits of measuring the grid across the rupture (localized necking, edges conjunction,...). Therefore, the obtained FLCs represent a reasonable upper bound limit for the material formability. In particular, the material can withstand deformations below the curve, while above the risk of rupture increases with the distance from the curve.

Figure 2 reports the FLC obtained at $20^{\circ} \mathrm{C}$ and $300^{\circ} \mathrm{C}$ and shows a significant increasing of the material formability already at warm temperature. Moreover, they do not depend on the rolling direction in accordance with the annealed furniture status.

\section{FEM Model}

The results obtained from the characterization of the material were used to develop a FE model to simulate the stamping process of the $\mathrm{Ti}$ alloy sheet. In particular, the adopted methodology consists in two phases. In the first phase the model is used to simulate the Nakazima test and its results are compared with the experimental ones in order to evaluate its reliability in forecasting the sheet failure. Once validated, the model is used in the second phase to study the formability of the actual automotive part.

3.1. Models Description. The model was developed using the PamStamp2G explicit code and it is reported in Figure 3 and Table 1. In both simulations of the Nakazima test (Figure 3(a)) and part stamping (Figure 3(b)), it consists of a die, blank-holder, sheet, and punch. In addition, a drawbead and symmetry planes were used for simulating the Nakazima tests in order to, respectively, prevent the sheet sliding and to take advantage of the process symmetry. In particular, the drawbead is defined using the restraining force $(F r)$ and opening force $(F o)$ parameters that represent the force per length unit that act on the sheet and the blankholder, respectively. All the parts were modelled using shell elements. Die, punch, and blank-holder were considered as rigid bodies, while the sheet was considered as plastic isotropic body. With regard to the solving settings, five integration points within the sheet thickness were set and automatic adaptive remeshing algorithm was used taking into account local curvature and deformation level criteria. 


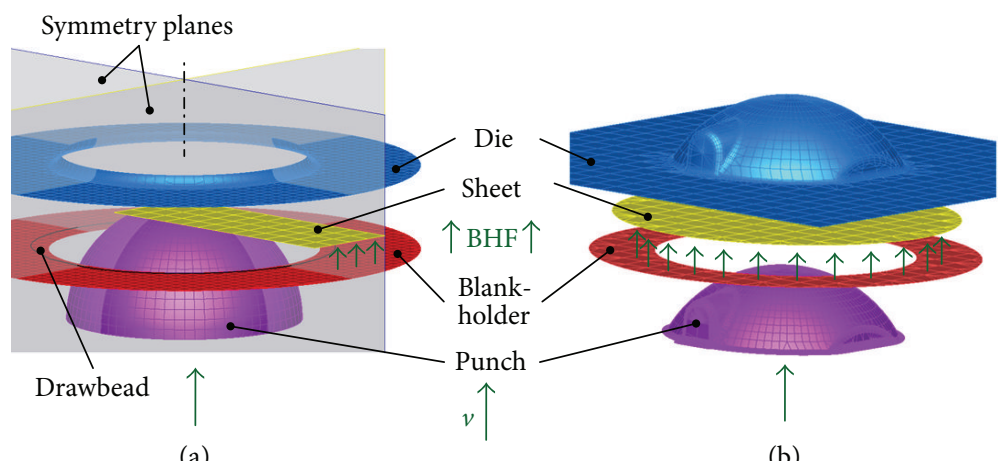

(a)

(b)

Figure 3: FEM models of (a) Nakazima test and (b) part drawing.

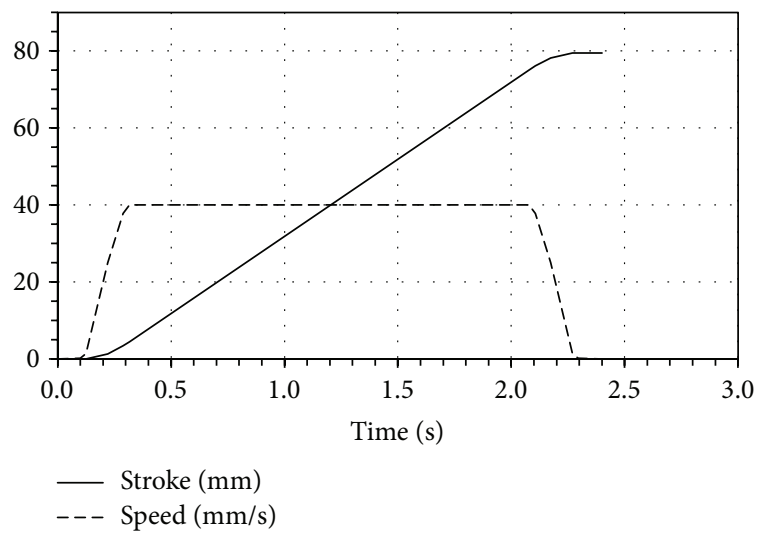

FIGURE 4: Punch movement curves.

TABle 1: Process parameters.

\begin{tabular}{|c|c|c|}
\hline & $20^{\circ} \mathrm{C}$ & $300^{\circ} \mathrm{C}$ \\
\hline \multicolumn{3}{|l|}{ Material properties } \\
\hline Sheet & \multicolumn{2}{|c|}{ Ti CP GR.2 annealed - 1 mm } \\
\hline \multirow[t]{2}{*}{ Dimensions $[\mathrm{mm}]$} & $\begin{array}{l}\text { Nakazima: } \\
\text { (width) }\end{array}$ & $\begin{array}{c}12-36-84 \\
100-132-150\end{array}$ \\
\hline & Stamping: & $\varnothing 360$ \\
\hline Young Module [GPa] & 106 & 88 \\
\hline $\begin{array}{l}\text { Flow stress } \\
\sigma=k \cdot \varepsilon^{n}\end{array}$ & $\begin{array}{l}k=640 \\
n=0.12\end{array}$ & $\begin{array}{l}k=204 \\
n=0.13\end{array}$ \\
\hline Failure criterion & \multicolumn{2}{|c|}{ FLC } \\
\hline \multicolumn{3}{|l|}{ Process } \\
\hline$v[\mathrm{~mm} / \mathrm{s}]$ & \multicolumn{2}{|c|}{40} \\
\hline $\mathrm{BHF}[\mathrm{kN}]$ & 20 & 5 \\
\hline Sheet friction & \multicolumn{2}{|c|}{$T=\mu N$} \\
\hline Contact with punch $\mu=$ & 0.12 & 0.45 \\
\hline Other contacts $\mu=$ & 0.12 & 0.35 \\
\hline
\end{tabular}

During the process, the punch moves at a constant velocity $(40 \mathrm{~mm} / \mathrm{s})$ and acceleration ramps were used to avoid kinematic instability in the simulation (Figure 4). The blankholder force (BHF) was kept constant during all the process and pretest simulations were used to set its proper value.
In particular, it was set equal to the minimum value that ensures obtaining sound parts without wrinkling. This allows us to avoid an excessive sheet flow limitation which leads to an excessive stretching of the sheet and increases the risk of fracture. Since the flow law of the material and the friction conditions are temperature dependent, different BHF values have to generally be predetermined for cold and warm forming.

Data available from the literature on material elastic module [24], tensile tests, and the previously estimated FLCs were used in the simulations to characterize the behaviour of Ti CP Gr.2 $1 \mathrm{~mm}$ thick alloy sheet at room and warm temperature $\left(20^{\circ} \mathrm{C}\right.$ and $\left.300^{\circ} \mathrm{C}\right)$. The hypotheses of a good lubrication at room temperature [25] and of a not efficient lubrication at warm temperature [26] were chosen and the Coulomb friction model was adopted (see Table 1).

Details on material characteristics, friction, samples dimensions, and other process parameters are reported in and Table 1.

3.2. FEM Model Validation. The results of the Nakazima tests were used to validate the capability of the FE model. In particular, the rupture position and the thickness distribution $t(s)$ along the specimen profiles at failure (Figure 5(a)) were considered for the comparison.

The FEM furnishes the results of the sheet thickness as a function of the mesh elements located at the sheet membrane; therefore, it was necessary to extract and elaborate the data in order express the thickness distribution as a function of the curvilinear abscissa $s$ as reported in Figure 5.

The steps of the described algorithm were implemented in a software code (Figure 5(b)).

(i) Mesh data is extracted from the FEM output file (elements, thickness, and nodes coordinates).

(ii) Estimation of the FEM thickness as a function of the membrane nodes $t_{0}(x, y, z)$. The sheet thickness is associated with the elements of the membrane mesh; therefore, data were elaborated to obtain the thickness in relation with the coordinates of the membrane nodes. In particular, the thickness was estimated as the average thickness of the elements that the node belongs to and, since the elements have 


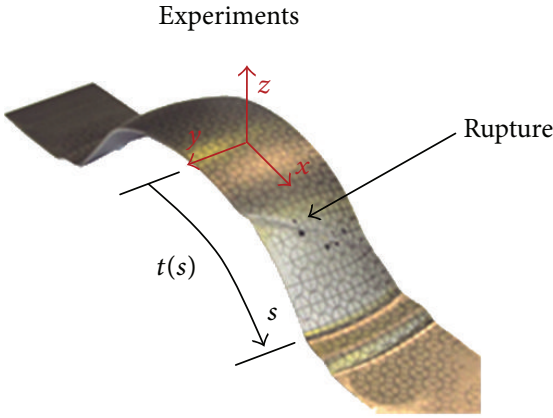

(a)
FEM (data extraction)

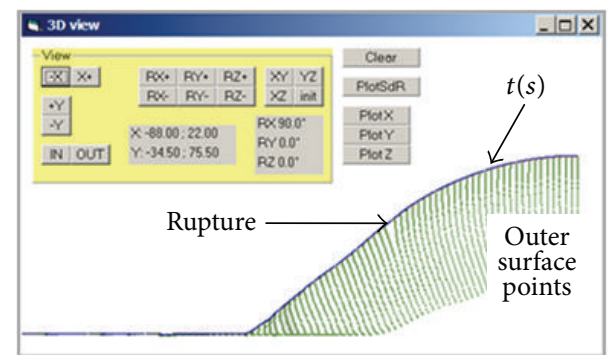

(b)

Figure 5: Measurements of the final thickness along the part profile in (a) experiments and (b) software for FEM data extraction.

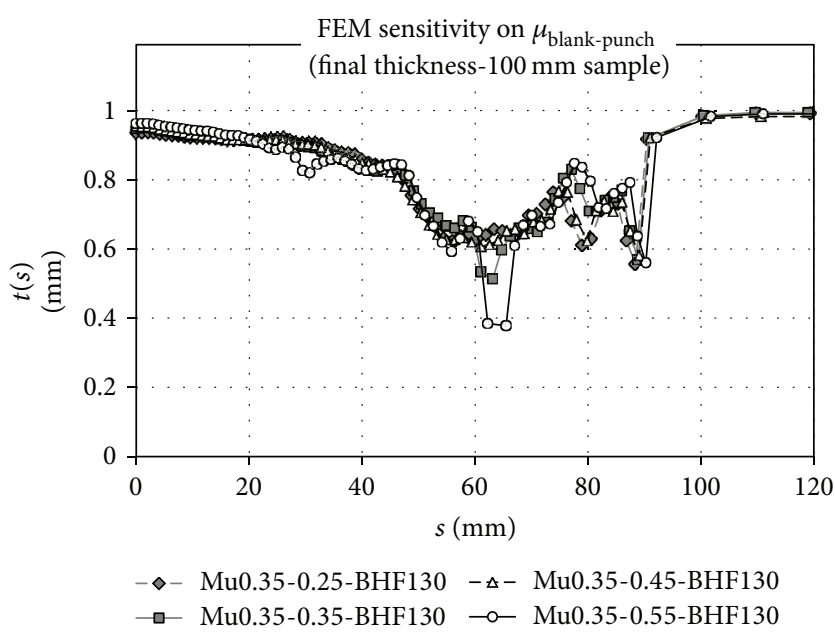

(a)

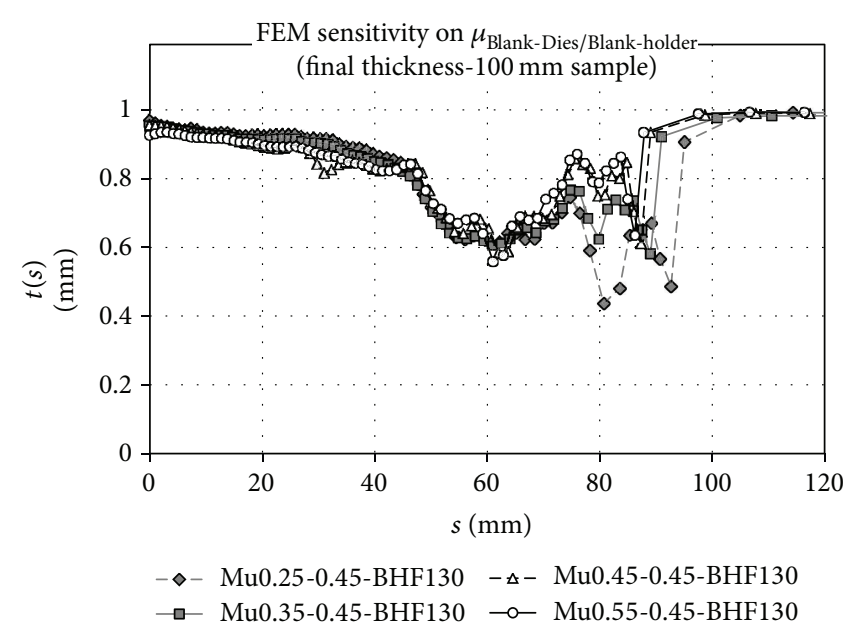

(b)

FIGURE 6: Sensitivity of the FE model on the friction coefficient between the sheet and (a) punch and (b) dies and blank-holder. A constant blank-holder force $(\mathrm{BHF}=1300 \mathrm{kN})$ was used.

different dimensions, the average value was weighted according to the element areas.

(iii) Estimation of the FEM thickness in correspondence with the outer surface $t(x, y, z)$. The experimental measures are performed considering the profile of the outer surface; therefore, the membrane nodes are offset of a value equal to half of the local thickness so to define the outer surface.

(iv) Recognition of the nodes that belong to the desired profile (i.e., $X Z$ plane in Figure 5) and interpolation using a SPLINE function (Hermite method was adopted).

(v) Estimation of the curvilinear abscissa $t(s)$ as the length of the SPLINE passing through the nodes.

Once the thickness in each node and its position along the considered profile are known, it is possible to plot and compare the FEM and experimental thickness results.

Before performing the comparison between FEM and experiments, the sensitivity of the model with respect to the process parameters was investigated. In particular, the friction coefficient (Figure 6), the blank-holder force (BHF, Figure 7), and the drawbead parameters ( $F r$ and Fo, Figure 8) were considered.

The thickness profiles do not show significant differences when changing the friction coefficients between sheet and punch (Figure 6(a)) and between sheet, die, and blank-holder (Figure 6(b)). Moreover, when the BHF is considered, the use of high values $(\mathrm{BHF}=1900 \mathrm{kN})$ hampers the material flow and anticipates the sheet rupture, while for lower values $(\mathrm{BHF}=1300 \mathrm{kN}$ and $700 \mathrm{kN})$ it becomes not influent. On the contrary, the model is significantly sensible to $\mathrm{Fr}$ and $\mathrm{Fo}$ variation (Figure 8). In fact, both the thickness profile and the point of failure on the sheet vary as their values change.

According to the achieved results, the model was calibrated testing different $F r$ and Fo values and keeping constant the friction coefficients and the BHF ( $\mu_{\text {Punch }}=0.45$, $\left.\mu_{\text {Die } / \text { Blank-holder }}=0.35, \mathrm{BHF}=1300 \mathrm{kN}\right)$. In particular, the calibration was performed considering different specimen lengths and temperatures. Figure 9 reports an example of the achieved results for the $100 \mathrm{~mm}$ width sample at cold and warm temperatures. The good overlapping between 


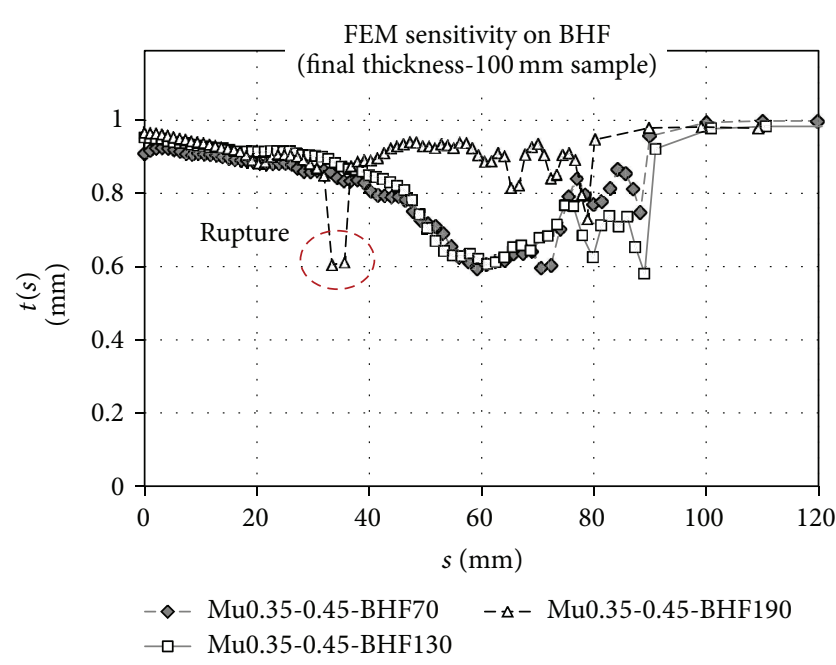

FIGURE 7: Sensitivity of the FE model on the blank-holder force (BHF).

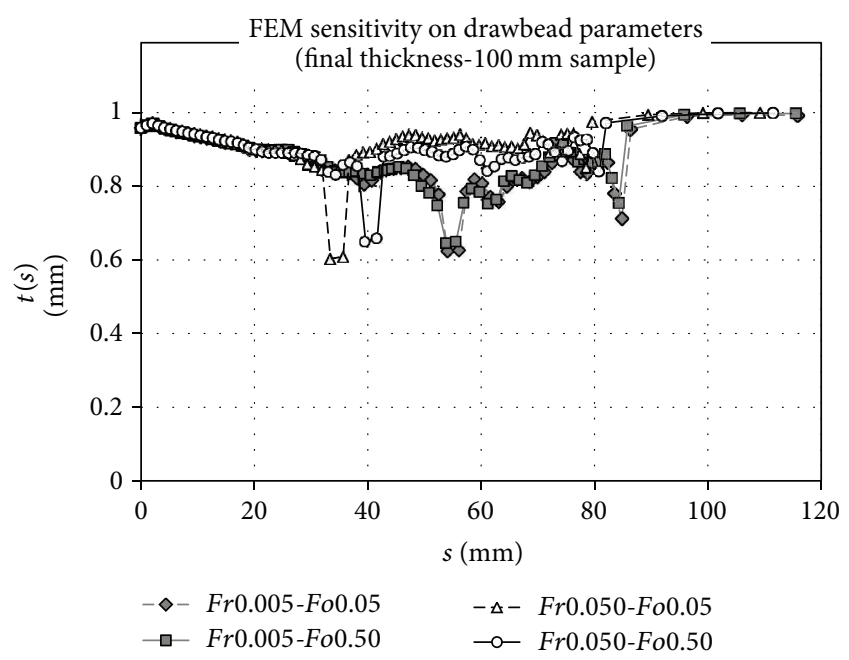

FIGURE 8: Sensitivity of the FE model on the drawbead Fr and Fo values.

experiments and FEM simulations confirms the capability of the model to properly forecast the material behaviour during the deformation process. The results of the thickness profiles and the rupture positions prove that the FE model is able to predict both the material flow and the sheet failure, respectively. Moreover, the low influence of the friction coefficients and the BHF on the final results show that the model is robust with respect to these parameters when the part thickness and rupture are considered.

\section{Feasibility Study of a Differential Gear Box}

4.1. Case Study. The part chosen for the feasibility study is the cover of a differential gear box (Figure 10) mounted on medium size trucks whose geometry showed some criticality during the cold forming process that lead to failure of the part if produced in a single deformation stage. In fact, it is characterised by three different geometrical features that have their complexity: the spherical dome that presents a high drawing depth, the two lateral sides presenting an almost vertical orientation, and the "nose" that is a protrusion with small radius values where the material flow is limited during the stamping process giving rise to high localised deformations with consequent high risk of sheet failure.

In order to overcome the lower formability of the $\mathrm{Ti}$ alloy at room temperature (Figure 2), warm forming was considered to realize the part. Therefore, the part stamping was simulated at both room $\left(20^{\circ} \mathrm{C}\right)$ and warm temperature $\left(300^{\circ} \mathrm{C}\right)$ so to evaluate the feasibility of the part stamping at higher temperature and to evidence the differences existing between the two working conditions. In particular, the maximum deformations of the sheet, its thinning, and the forces required by the punch and the blank-holder to complete the deforming operation without unacceptable sheet wrinkling and failure were considered.

4.2. FEM Simulations and Results. The developed FE model was used to study the feasibility of the part simulating the forming process at the different temperatures according to the details reported in Figure 3(b) and Table 1. The results were evaluated considering different aspects on the final part: absence of wrinkles, absence of failure, and final thickness distribution.

The use of a blank-holder prevents the wrinkles formation but reduces the part formability since it retains the material flow, increasing the risk of sheet rupture. Therefore, wrinkles and failure represent upper and lower bounds, respectively, for the BHF. For these reasons, preliminary simulations were run varying the $\mathrm{BHF}$ so to identify the minimum values required to avoid wrinkles on the part. Results (Figure 11) show that a force equal to $20 \mathrm{kN}$ is required in cold forming while $5 \mathrm{kN}$ are required at warm temperature. The so identified values were then used to simulate the part stamping at cold and warm temperatures.

Figure 12 reports the results of the simulation at $20^{\circ} \mathrm{C}$. It is possible to observe that the highest thinning is located on the protrusion where it reaches the $16 \%$ in correspondence with the fillet radius, while thinning is lower on the dome and side features and it does not exceeds the $6 \%$. With regard to the membrane deformations, they are beyond the FLC. In particular, the critical points are on the protrusion feature showing a higher risk of sheet rupture in this area.

Figure 13 reports the results of the simulation at $300^{\circ} \mathrm{C}$. In this case, the thinning on the part is similar to cold forming, but it reaches higher values (21\%) that are located on the flat area of the protrusion. With regard to the membrane deformations, they are far below the FLC at warm temperature and the risk of rupture is very low on the whole part.

Finally, Figure 14 shows the slopes of the punch force required by the forming process in cold and warm forming.

By comparing the results in Figures 11-13, it is possible to observe that the protrusion represents the most critical feature to be formed on the part while, besides their complexity, the dome and the sides do not show any criticality 


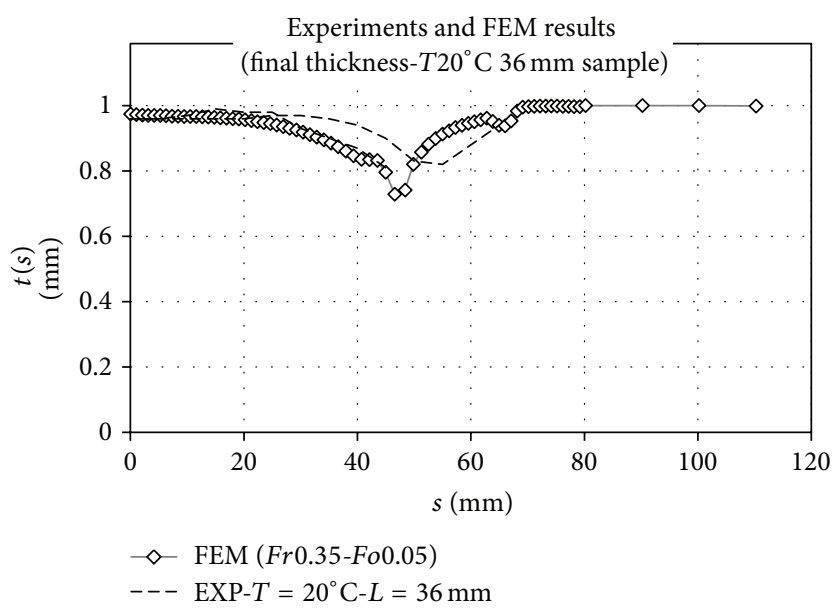

(a)

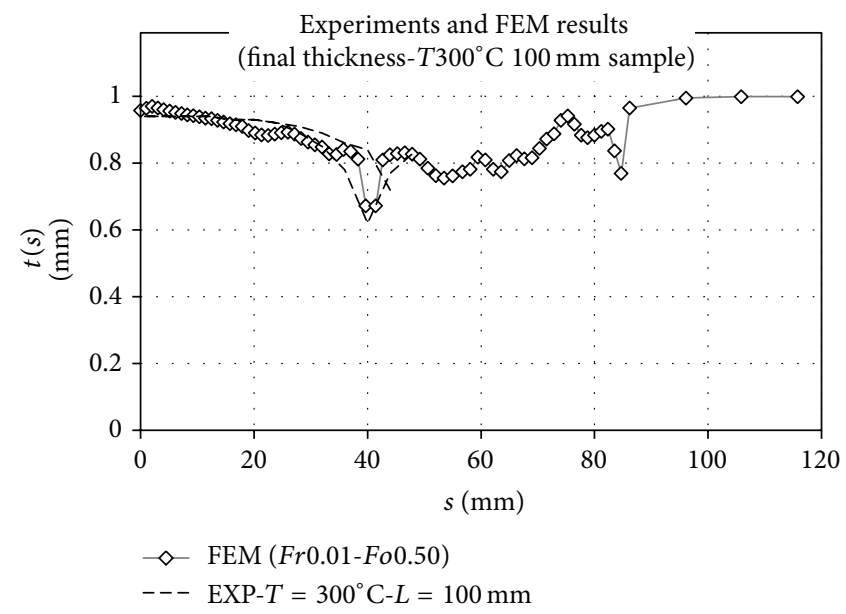

(b)

FIGURE 9: Comparison with experiment and FEM results at (a) cold and (b) warm temperatures.
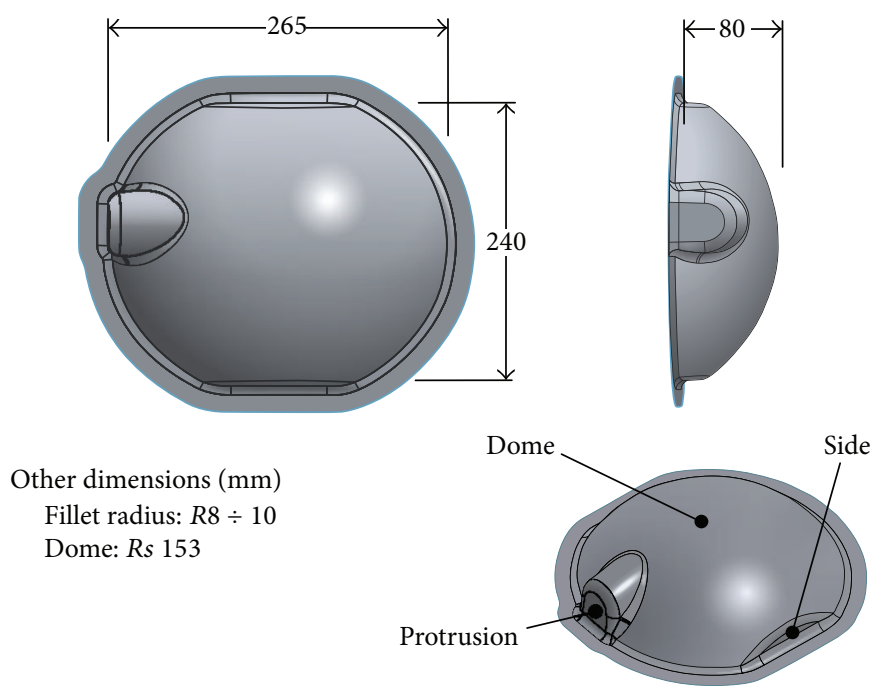

FIGURE 10: Geometry of the differential gear box.

in terms of formability. In particular, the deformations in the protrusion area are too severe and go beyond the formability limit represented by the FLC. A lower BHF should be used to improve the sheet sliding and to reduce the deformations, but the wrinkles formation does not allow us to adopt that solution. As a result, the part cannot be cold formed. On the contrary, the results of warm stamping show that the part is feasible at $300^{\circ} \mathrm{C}$. In fact, the use of a lower $\mathrm{BHF}$ allows us to overcome the material holdback that could derive from the higher friction coefficient at the sheet-die and sheet-blank-holder interfaces (Table 1). As a result, the point clouds in Figures 12 and 13 show that the global membrane deformations are similar but, thanks to the higher FLC at $300^{\circ} \mathrm{C}$ (Figure 2), the part can be stamped without defects. Moreover, it has a moderate final thinning (21\%) which is distributed on a wider area thanks to a more uniform material flow. Finally, warm forming allows us to significantly reduce the stamping force.

\section{Conclusions}

The high strength to density ratio of Titanium alloys makes them suitable for applications where lightweight material are requested as in the case of automotive part manufacturing. In fact, the use of Titanium instead of steel alloys allows a weight reduction of about $42 \%$ on the same part. On the other hand, they are hard to form at cold temperature and hot forming leads to problems as the material properties change. Warm forming represents a good solution even if there is a lack in the material characterisation, especially when formability criteria are considered. In particular, these criteria have a great importance for the development of FEM models that 

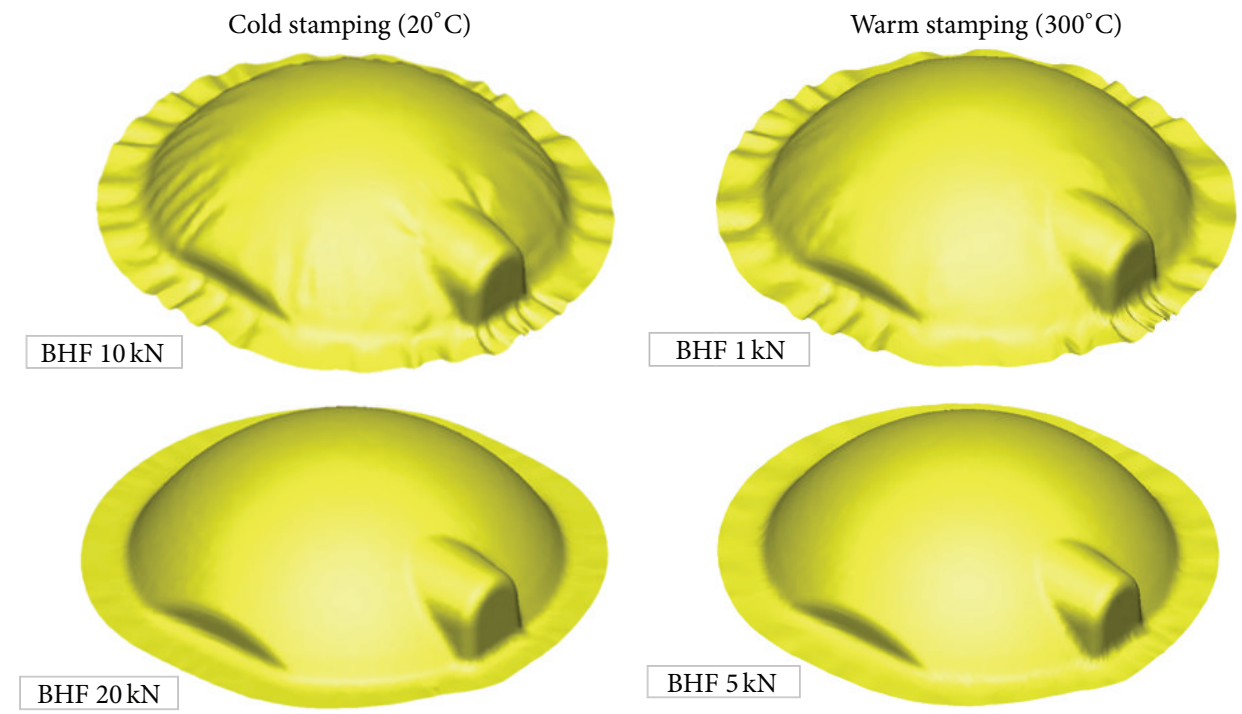

FIGURE 11: Influence of BHF on the wrinkling of the stamped part.
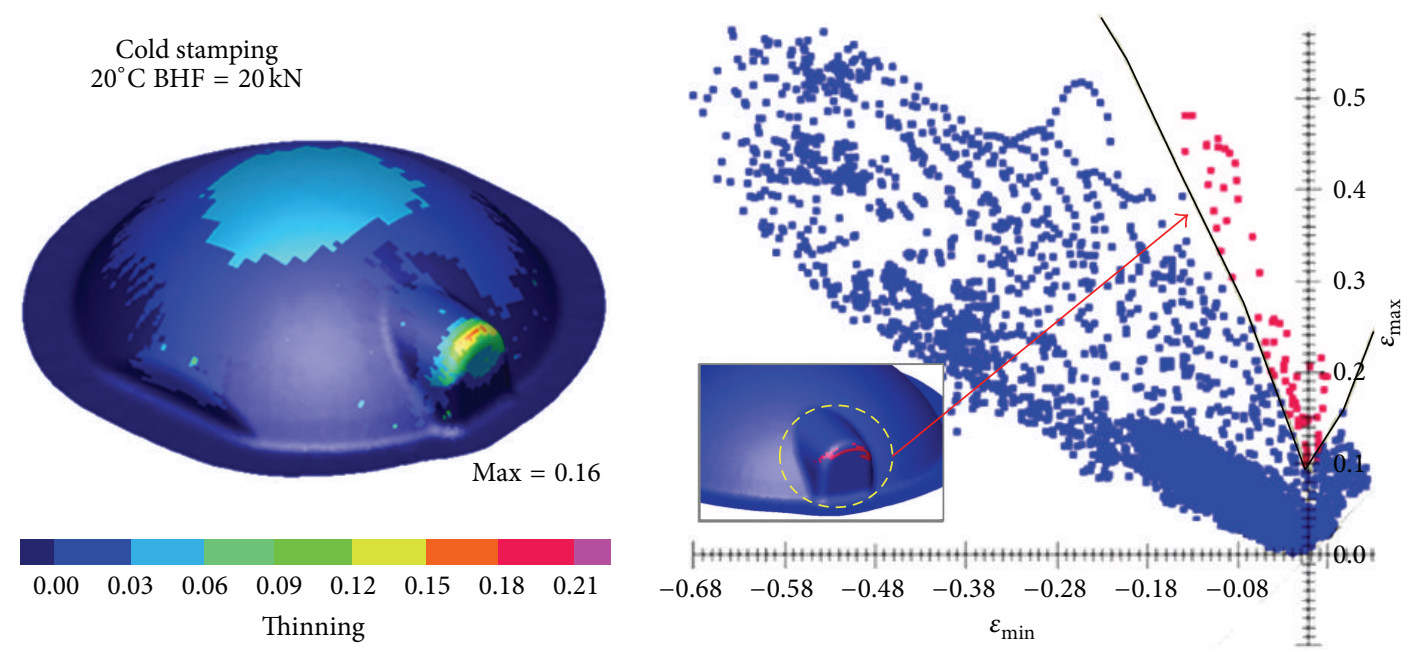

FIGURE 12: Formability (FLC) and thinning in cold forming of the part $\left(20^{\circ} \mathrm{C}-\mathrm{BHF}=20 \mathrm{kN}\right)$.

represent a useful tool for designers and technicians that aims at developing new products using Ti alloys. In fact, they allow us to reduce the time and the costs required by the part design, but they require a good characterization of the material formability and they need to be validated before considering their results as reliable.

For this reasons, this paper focused on stamping of $\mathrm{Ti}$ sheet alloy and proposed a methodology that can be used to develop a reliable FEM model for studying the forming process. In particular,

(i) the method consists in the use of Nakazima test to both characterise the material formability and to validate the model;

(ii) results of the test are used to develop a FEM model and to validate its reliability in estimating the material flow and in forecasting the sheet rupture.
The method was applied to the study of Ti CP GR.2 sheets stamping of a gearbox characterized by a complex geometry. In particular,

(i) the FLC of the material were estimated and the FEM model was developed at cold and warm temperatures;

(ii) the FEM model was used to study the stamping process identifying the limit of the cold forming process and giving information on the feasibility of the part at warm temperature.

The results showed that

(i) the proposed method showed to be useful for developing a FEM model of a stamping process using the least number of experiments and without wasting resources in realizing dies and tools for its validation or spending them in trial and error approaches; 

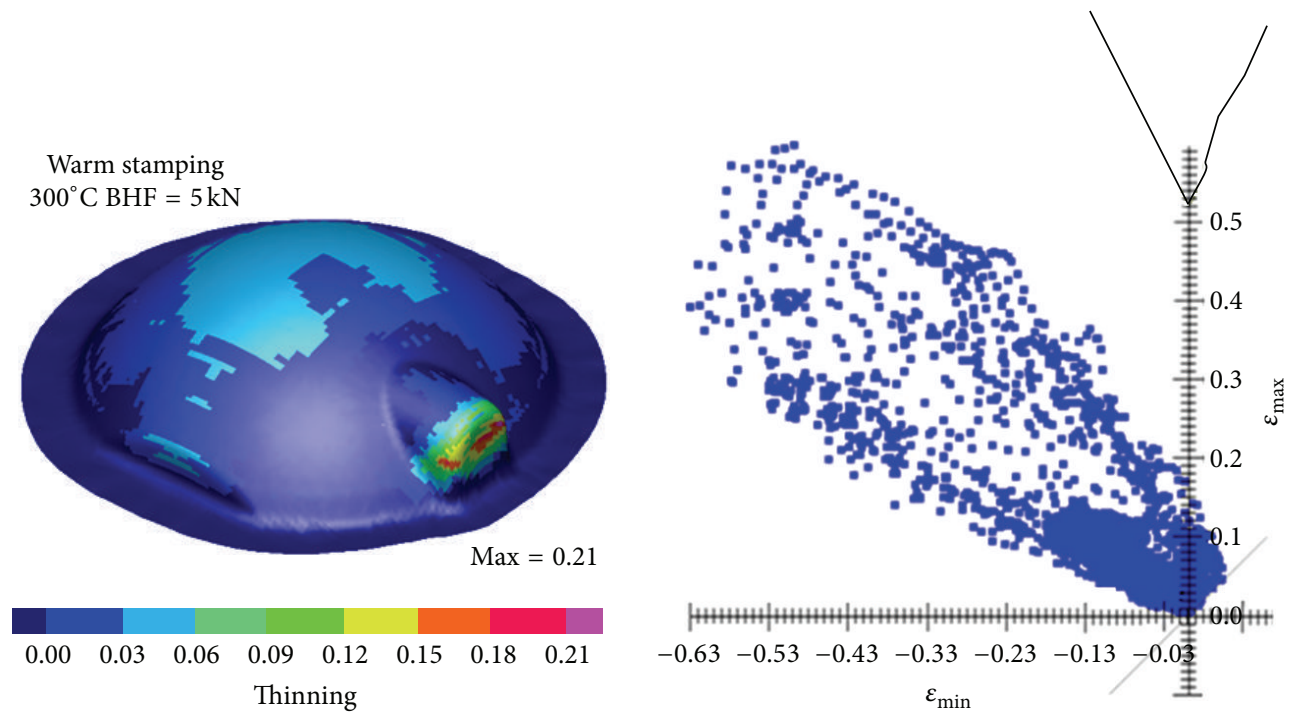

FIGURE 13: Formability (FLC) and thinning in warm forming of the part $\left(300^{\circ} \mathrm{C}-\mathrm{BHF}=5 \mathrm{kN}\right)$.

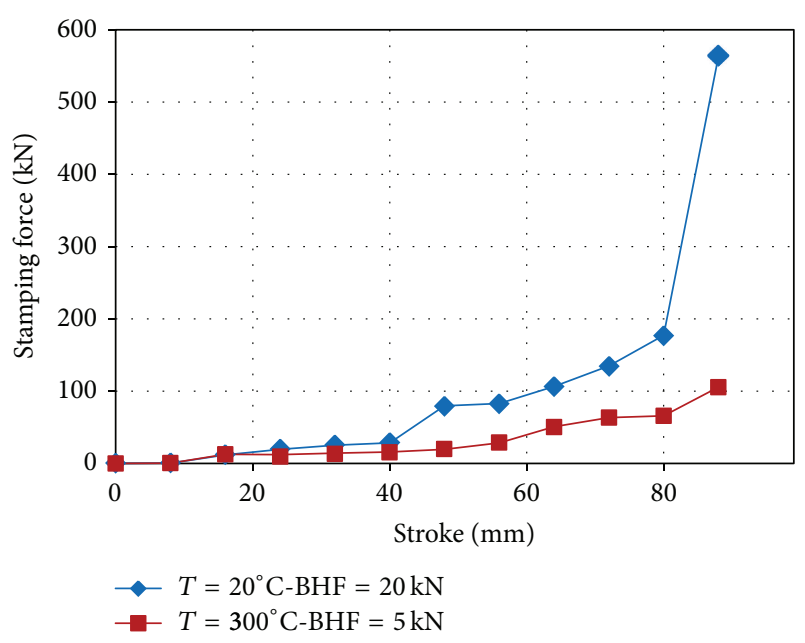

FIGURE 14: Stamping forces during cold and warm stamping of the part.

(ii) the higher formability of the material at $300^{\circ} \mathrm{C}$ showed by the FLC allows us to withstand more severe membrane deformations and thinning without breaking.

\section{Conflict of Interests}

The authors declare that there is no conflict of interests regarding the publication of this paper.

\section{References}

[1] D. Li, A. K. Ghosh, and X. Xia, Warm forming of Aluminium sheet-a review [Ph.D. dissertation], Department of Materials Science and Engineering, University of Michigan, 2008.
[2] A. Cigada, "Titanio e leghe di titanio," in Struttura e proprietà dei materiali metallici, T. Pastore, Ed., pp. 357-368, McGrawHill, Milano, Italy, 2012.

[3] R. R. Boyer, Materials Properties Handbook: Titanium Alloys, edited by: G. Welsch, R. Boyer, E. W. Collings, ASM International, Materials Park, Ohio, USA, 1994.

[4] R. R. Boyer, "Attributes, characteristics, and applications of titanium and its alloys," JOM, vol. 62, no. 5, pp. 21-24, 2010.

[5] M. Mitsuishi, J. Cao, P. Bartolo et al., "Biomanufacturing," Annals of the CIRP, vol. 42, no. 2, pp. 585-606, 2013.

[6] J. M. Donachie, Titanium: A Technical Guide, ASM International, Materials Park, Ohio, USA, 2nd edition, 2000.

[7] C. P. Lai, L. C. Chan, C. L. Chow, and K. M. Yu, "Warm-forming of light-weight alloys under multi-stage forming process," Advanced Materials Research, vol. 83-86, pp. 88-93, 2009.

[8] F. Ozturk, R. E. Ece, N. Polat, and A. Koksal, "Effect of warm temperature on springback compensation of titanium sheet," Materials and Manufacturing Processes, vol. 25, no. 9, pp. 10211024, 2010.

[9] R. Neugebauer, T. Altan, M. Geiger, M. Kleiner, and A. Sterzing, "Sheet metal forming at elevated temperatures," CIRP AnnalsManufacturing Technology, vol. 55, no. 2, pp. 793-816, 2006.

[10] F.-K. Chen and K.-H. Chiu, "Stamping formability of pure titanium sheets," Journal of Materials Processing Technology, vol. 170, no. 1-2, pp. 181-186, 2005.

[11] G. M. Goodwin, "Application of strain analysis to sheet metal forming problems," La Metallurgia Italiana, vol. 60, pp. 767-771, 1968.

[12] P. Teixeira, A. D. Santos, F. M. A. Pires, and J. M. A. C. de Sá, "Finite element prediction of ductile fracture in sheet metal forming processes," Journal of Materials Processing Technology, vol. 177, no. 1-3, pp. 278-281, 2006.

[13] A. Makinouchi, "Sheet metal forming simulation in industry," Journal of Materials Processing Technology, vol. 60, no. 1-4, pp. 19-26, 1996. 
[14] S. Yang and K. Nezu, "Application of an inverse FE approach in the concurrent design of sheet stamping," Journal of Materials Processing Technology, vol. 79, no. 1-3, pp. 86-93, 1998.

[15] E.-L. Odenberger, J. Hertzman, P. Thilderkvist et al., "Thermomechanical sheet metal forming of aero engine components in Ti-6Al-4V-PART 1: material characterisation," International Journal of Material Forming, vol. 6, no. 3, pp. 391-402, 2013.

[16] A. T. Santhanam and R. E. Reed-Hill, "The influence of strain rate dependent work hardening on the necking strain in $\alpha$ titanium at elevated temperatures," Metallurgical and Materials Transactions B, vol. 2, no. 9, pp. 2619-2622, 1971.

[17] D. R. Shouler and J. M. Allwood, "Design and use of a novel sample design for formability testing in pure shear," Journal of Materials Processing Technology, vol. 210, no. 10, pp. 1304-1313, 2010.

[18] S. Venugopal, P. Venugopal, and S. L. Mannan, "Optimisation of cold and warm workability of commercially pure titanium using dynamic materials model (DMM) instability maps," Journal of Materials Processing Technology, vol. 202, no. 1-3, pp. 201-215, 2008.

[19] O. N. Senkov and J. J. Jonas, "Dynamic strain aging and hydrogen-induced softening in alpha titanium," Metallurgical and Materials Transactions A, vol. 27, no. 7, pp. 1877-1887, 1996.

[20] P. F. Bariani, S. Bruschi, and A. Ghiotti, "Critical issues in the simulation of hot forming operations," Production Engineering, vol. 4, no. 4, pp. 407-411, 2010.

[21] E.-L. Odenberger, M. Oldenburg, P. Thilderkvist, T. Stoehr, J. Lechler, and M. Merklein, "Tool development based on modelling and simulation of hot sheet metal forming of Ti-6Al4V titanium alloy," Journal of Materials Processing Technology, vol. 211, no. 8, pp. 1324-1335, 2011.

[22] J. D. Embury and J. L. Duncan, "Formability maps," Annual Review of Materials Science, vol. 11, pp. 505-521, 1981.

[23] ASTM International, ASTM E2218-2-14, Standard Test Method for Determining Forming Limit Curves, ASTM International, West Conshohocken, Pa, USA, 2014.

[24] The Engineering ToolBox, Young Modulus of Elasticity for Metals and Alloys, The Engineering ToolBox, 2014, http://www .engineeringtoolbox.com/.

[25] A. F. Yetim, "Investigation of wear behavior of titanium oxide films, produced by anodic oxidation, on commercially pure titanium in vacuum conditions," Surface and Coatings Technology, vol. 205, no. 6, pp. 1757-1763, 2010.

[26] J. Adamus, "Theoretical and experimental analysis of the sheettitanium forming process," Archives of Metallurgy and Materials, vol. 54, no. 3, pp. 705-709, 2009. 

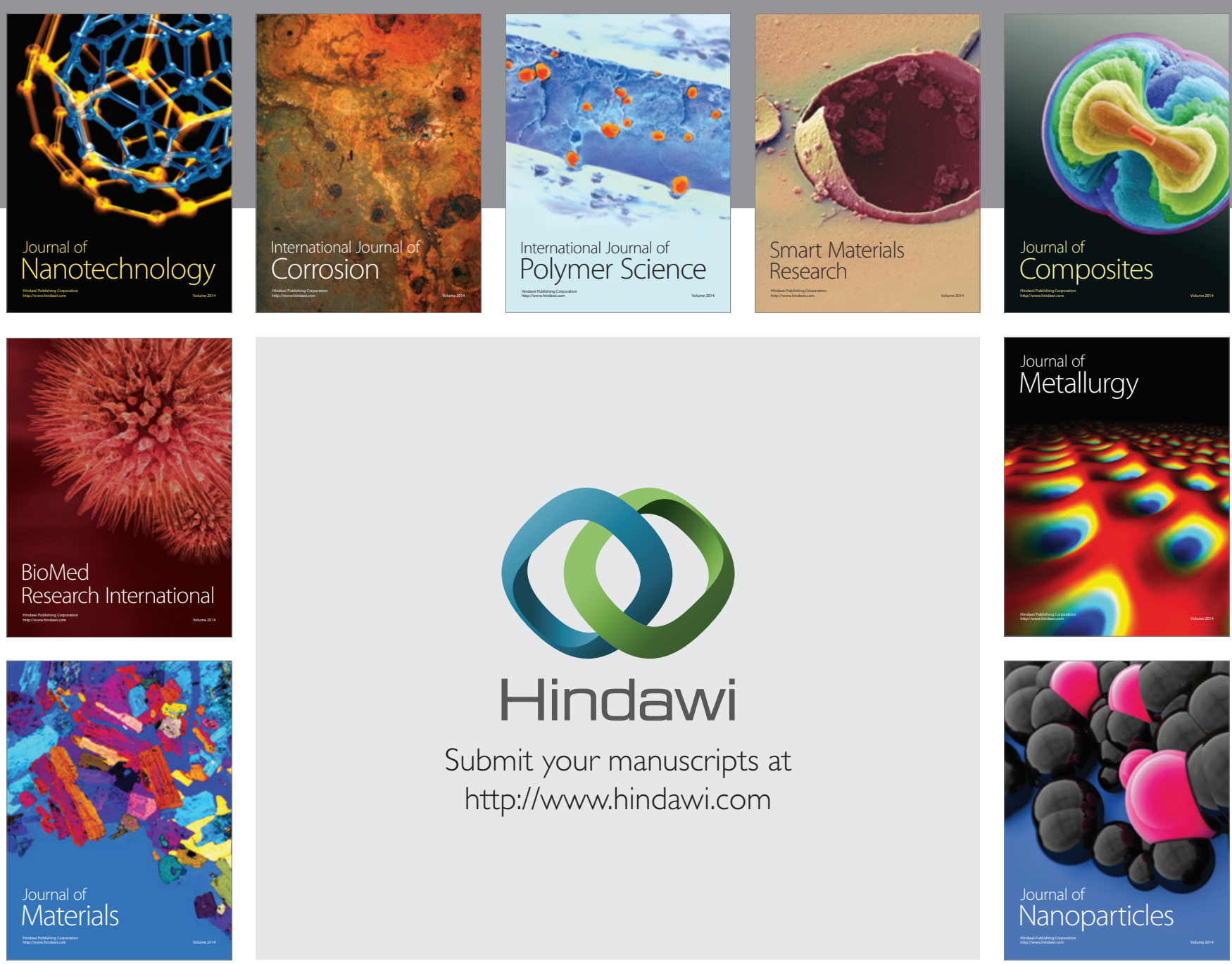

Submit your manuscripts at http://www.hindawi.com
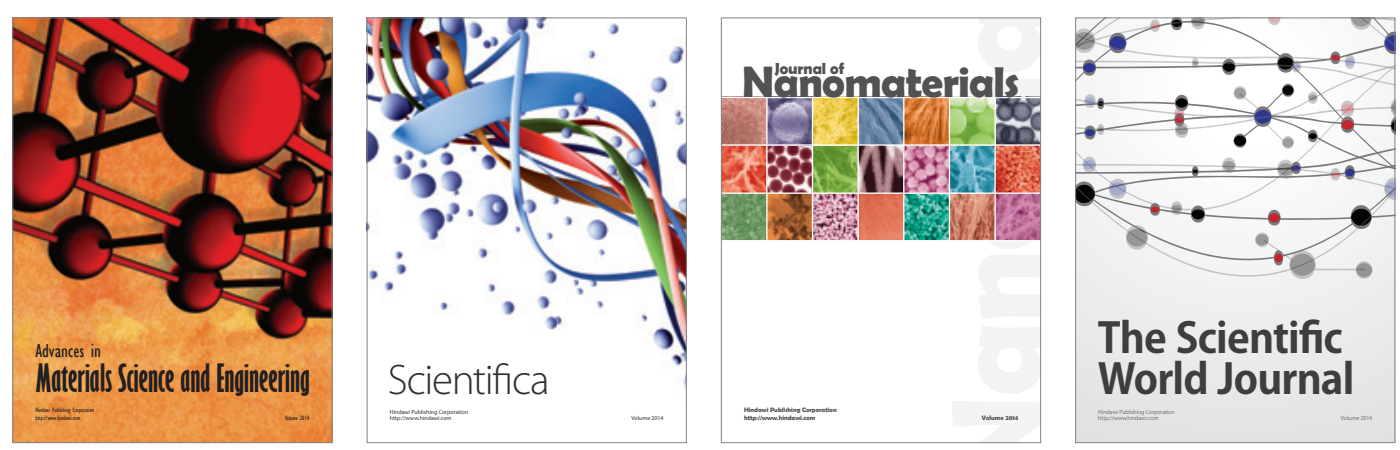

\section{The Scientific World Journal}
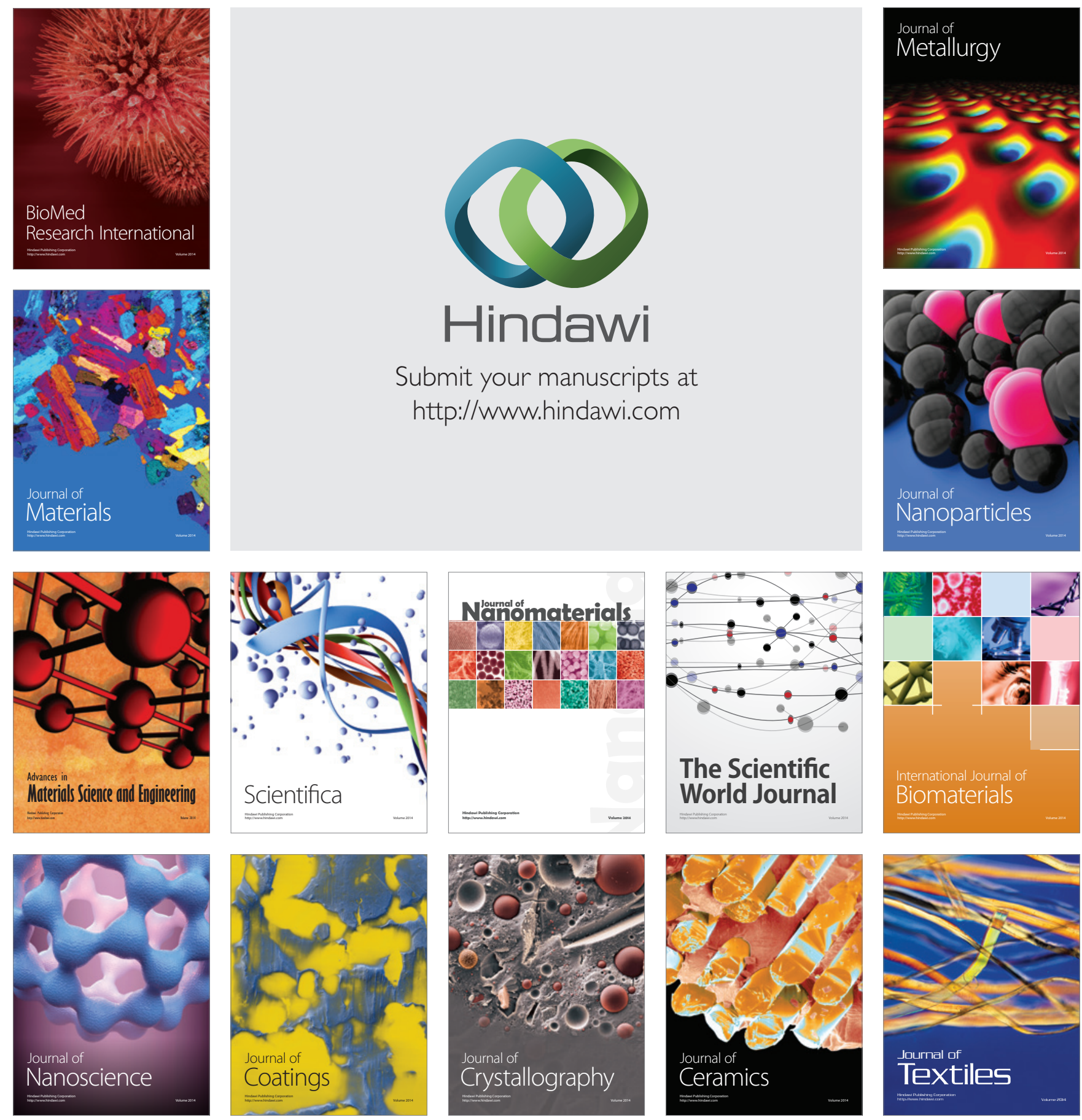